\title{
Prevalence of Occupational Health Consequences During Sugarcane Harvesting Among Harvesters of Morang District
}

\author{
Bijay Thapa, ${ }^{1}$ Archana Sharma ${ }^{2}$ \\ ${ }^{1}$ Department of Community Health Science, Patan Academy of Health Sciences, Lalitpur, Nepal, ${ }^{2}$ Department of \\ Ophthalmology, Nepal Eye Hospital, Tripureshwor, Kathmandu, Nepal.

\begin{abstract}
Background: Introduction: Sugarcane harvesting is widely practiced in Nepal. While harvesting most of the farmers are affected regularly with small bruises, cuts, wounds, lacerations and sometimes major cut injury or even an amputation of fingers. This study aims to find the prevalence of occupational health consequences among sugarcane harvesters during the sugarcane harvesting time. Methods: The descriptive cross sectional study was conducted at Bhaudaha VDC which is now incorporated in Katahari rural municipality, Morang. Sample size was 96 during the two weeks of study from December 2014. Convenient sampling method was used. Ethical approval was cleared from the Institutional Review Committee. Results: Most of the sugarcane harvesters were male comprising 83.3 percent. Mean age among them was 31.71 . Eighty six percent of harvester had nasal congestion, $67.7 \%$ had minor cuts whereas approximately $4.2 \%$ of them had major cuts. Shoulder joint, wrist joint, neck joint and low back pains were the mostly encountered musculoskeletal pain. Personal protective measures were not used by $33.3 \%$ of the harvesters. Conclusions: Occupational health consequences among sugarcane harvesters were mostly related to the musculoskeletal problems, respiratory problems, minor cuts, major cuts and eye related problems.
\end{abstract}

Keywords: musculoskeletal pain; occupational health consequences; sugarcane harvesters.

\section{INTRODUCTION}

The sugarcane industry in Nepal is amongst the main contributor to the national economy. However, the exact date of sugarcane cultivation is unknown in Nepal. The production and processing of sugarcane is still a major source of employment in Nepal. People of Nepal had started sugarcane farming to make different sweet products. Sugarcane grows best in warm, sunny, frost-free weather. It needs fertile, well-drained soil and at least 1,500 millimeters of rain each year or access to irrigation supplies. ${ }^{1}$ Sugarcane plants will take approximately seven to nine months to mature, or be ready for consumption. At the time of harvesting it stands two to four meters tall. Sugarcane harvesting is widely practiced in Nepal which has been decreasing year by year as most of the workers are migrating to foreign countries for labor work. Sugar industry is one of the important agro-based industries in the world which directly contributes creating employment, income and social developments in the rural areas of the country. ${ }^{1}$

Regardless of geographic region variation, sugarcane was grown in hilly region as well as in Terai region. The favorable climatic and topographic conditions make the Terai region of Nepal a suitable region for sugarcane farming. People have commercial sugarcane farming nearby areas from mills. There have been seen many small scale sugarcane farms with many individual farmer for the generation of income. Mostly this small scale farms sale sugarcane in local market to make a juice and chewing directly. So, for that most of the farmers harvest sugarcane manually without any use of personal protective equipments. Sugarcane harvester is a person who is engaged in cutting, tie up \& loading of sugarcane in vehicle. While harvesting most of the farmers are affected regularly with small bruises, cuts, wounds, lacerations and sometimes major cut injury or amputation of fingers. Harvesting sugar cane requires excessive physical effort. The cutters may cut up to 12 tons of cane a day, involving bending the spine 3,994 times. $^{2}$

Farmers have many health problems during sugarcane cutting because of the lack of proper knowledge about equipments and proper safety use. Most of them are poor farmers who cannot afford those equipments therfore, they use

Correspondence: Dr. Bijay Thapa, Department of Community Health Science, Patan Academy of Health Sciences, Lalitpur, Nepal. Email: bijar25@gmail.com. Phone: +977-9842025297. DOI:10.3126/jcmsn.v15i2.23813. Article received: 2019-04-24. Article accepted: 2019-6-14. 
Thapa et al. Prevalence of Occupational Health Consequences During Sugarcane Harvesting..

local knifes and sickles for sugarcane cutting. These local equipments are hazardous contributing to numerous cuts and minor injuries. There are different conditions on the fields resulting in ergonomic problems. Mostly these workers encounter musculoskeletal disorder, repetitive work strain, and accidents. Musculoskeletal discomfort was found maximum in low back and knee for cane workers performing manual lifting and carrying task. Ergonomic intervention in the sugarcane cutting activity has shown less cutting force and stress on the body muscles of the sugarcane harvesters. ${ }^{3}$ This study aims to find the prevalence of occupational health consequences among sugarcane harvester during the sugarcane harvesting time.

\section{METHODS}

The cross sectional study was conducted at Bhaudaha VDC which is now incorporated in Katahari rural municipality, Morang for two weeks period in December 2014. Sample size was 96 after taking the population proportion of fifty percent and margin of error as ten percent and $95 \%$ of CI Therefore we obtained $n=96.04$ and considered it as a 96. Convenient sampling method was used. The data were collected using questionnaire after getting consent. Health status and symptoms were asked which occurred during the harvesting time period. Ethical approval was taken from the IRC of the Nobel Medical College. Sugarcane harvester was defined as a person who was engaged in cutting, tying up \& loading of sugar-cane in vehicle. Harvesters were contacted at their work place according to their suitable timing. They were explained about the importance, nature and objective of the study. Questionnaire were created using Microsoft word 2007. Analysis was done using Microsoft Excell 2007 and SPSS 16.0.

\section{RESULTS}

Total of 96 sugarcane harvesters were included in this study. Among them $83.3 \%$ were male as shown in Table 1. Sugarcane harvesters were from 16 to 61 years of age with mean age of 31.71 years and standard deviation of 12.12 . Illiterate population was $36.5 \%$. Main occupation of those harvesters was students and farmers consisting $69.2 \%$ and $42.7 \%$ respectively followed by laborer, rickshaw puller and housewife. Table 2 presents the occupational health consequences among the harvesters.

Foreign body in eye was the main occupational health hazard comprising $100 \%$. Sugarcane leaf dust

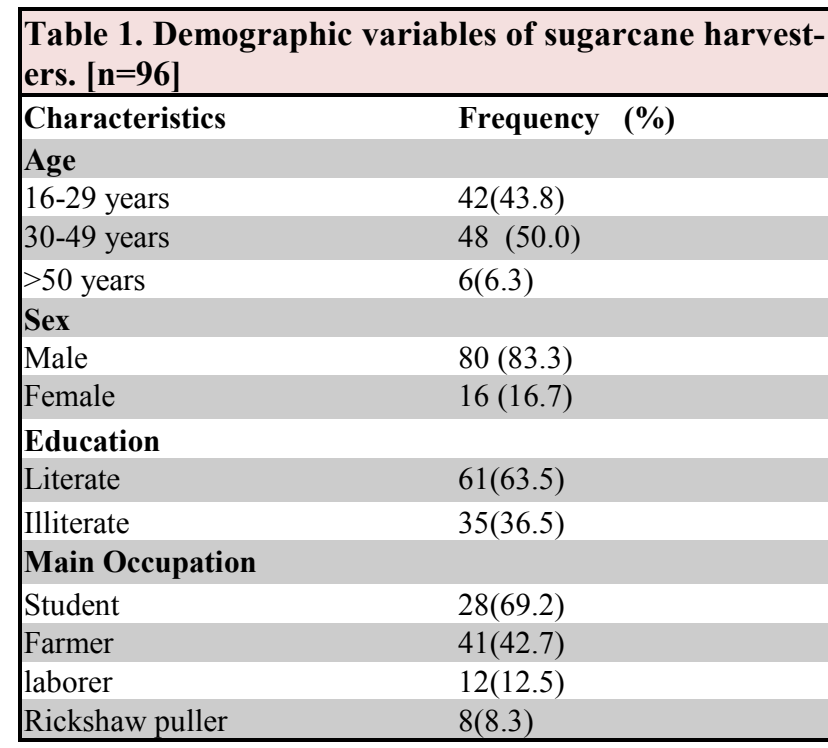

Table 2. Occupational health consequences among the harvesters. [n=96]

\begin{tabular}{|ll|}
\hline Characteristics & Frequency (\%) \\
Foreign body in eye & $100 \%$ \\
Sugarcane Leaf particles & $40(41.7)$ \\
Stem's particles & $24(25.0)$ \\
Mixed & $20(20.8)$ \\
Dust & $12(12.5)$ \\
Allergic conditions & \\
Skin and eye itching & $26(27.1)$ \\
Productive cough & $20(20.8)$ \\
Skin itching & $15(15.6)$ \\
Eye watering & $9(9.4)$ \\
Eye itching & $8(8.3)$ \\
Eye itching and dry cough & $6(6.3)$ \\
Skin and productive cough & $5(5.2)$ \\
Eye pain & $4(4.2)$ \\
Skin itching and dry cough & $3(3.1)$ \\
Nasal congestion & $83(86.5)$ \\
Headache & $66(68.7)$ \\
Minor cut & $65(67.7)$ \\
Nosebleed & $7(7.3)$ \\
Major cut & $4(4.2)$ \\
\hline
\end{tabular}

was the main type of foreign body found in eye comprising $41.7 \%$ followed by stem particles, mixed type and dust particles $25 \%, 20.8 \%$ and $12.5 \%$ respectively. Almost $86.5 \%$ of the harvesters had nasal congestion. Minor cut was seen among $67.7 \%$ of the harvesters whereas only $4.2 \%$ had a major cut. Nearly $68.7 \%$ of the harvesters had encountered headache. Allergic conditions are also shown in this table. Skin and eye itching were the most prevalent allergic conditions having in $27.1 \%$ of the harvesters followed by productive cough, skin itching, watering and eye itching comprising $20.8 \%$ and $15.6 \%, 9.4 \%$ and $8.3 \%$ respectively. Similarly, 
eye itching and dry cough, skin and productive cough, eye pain were found consisting $6.3 \%, 5.2 \%$, $4.2 \%$ and $3.5 \%$ respectively. Nose bleeding was seen in $7.3 \%$ of the harvesters. A mostly encountered occupational consequence related to the musculoskeletal pain is described in (Table 3).

\begin{tabular}{|lc|}
\hline $\begin{array}{l}\text { Table 3. Musculoskeletal joints involved pain during } \\
\text { harvesting. [n=96] }\end{array}$ \\
\hline Characteristics & Frequency (\%) \\
Shoulder joint & $91(94.8)$ \\
Neck joint & $89(92.7)$ \\
Hand/Wrist joint & $81(84.4)$ \\
Knee joint & $77(80.2)$ \\
Lower back joint & $74(77.1)$ \\
Elbow joint & $72(75.0)$ \\
Multiple joint & $64(66.7)$ \\
Ankle joint & $63(65.6)$ \\
\hline
\end{tabular}

Almost all of the harvesters had musculoskeletal pain. Shoulder joint pain was the most prevalent among $94.8 \%$ of the harvest followed by Neck joint (92.7\%), wrist joint $(84.4 \%)$, knee joint $(80.2 \%)$, lower back pain $(77.1 \%)$, elbow joint $(75.0 \%)$ and multiple joints (66.7\%) Ankle joint was less involved in pain having amongst $65.6 \%$ of harvesters. Personal protective measures used by harvesters have been depicted in (Table 4).

\begin{tabular}{|ccc|}
\hline $\begin{array}{l}\text { Table } \\
\text { harvesters. }[\mathbf{n}=96]\end{array}$ & protective & measures used by \\
\hline Types & Frequency (\%) \\
Mask & $01(1)$ \\
Cloth & $63(65.6)$ \\
None & $32(33.3)$ \\
\hline
\end{tabular}

Most of the harvesters (65.6\%) used cloth as a personal protective measure. Only one harvester used mask whereas $33.3 \%$ did not used any sort of protective measures.

\section{DISCUSSION}

In this descriptive cross-sectional study, we have found several types of occupational health consequences prevalent among sugarcane harvesters. Most of the prevalent occupational health consequences were related to the allergic conditions, eye related problems, nasal congestion, musculoskeletal pain, minor cuts and major cuts.

In our study, during the sugarcane harvesting process, the sugarcane workers swung their arms over their heads. They had to bent their bodies many times while cutting, pulling and loading sugarcane on the tractor. Such motions placed the average sugarcane harvester at risk of developing musculoskeletal pains because they often lead to both muscle spasms and poor blood circulation. Moreover, tendons, joints, and other soft tissues eventually became fatigued and subsequently injured. ${ }^{4}$ This finding was consistent with other studies, where repetitive motions of hand and other parts of body is said to be the cause for musculoskeletal pain. ${ }^{5}$ The other factor were the continuous awkward posture. Sugarcane workers repetitively pulled bunches of sugarcane, lifted them, and then threw them into the tractor. During the process they repeatedly moved their hands and feet and stabilized their positions which contributed them to the unusual awkward position. This type of excessive workloads was a hazard for both their muscles and tendon which maintained their body balance. This finding was similar to other studies conducted among rubber workers in Malaysia6 and farm workers in the United States.

Another important factor related to musculoskeletal pain was forceful exertion. Sugarcane harvesters were engaged in lifting bunches of sugarcane. Lifting and forceful movements also put these individuals at risk of developing musculoskeletal disorders which contributed to the lower back pain among harvesters. Most of the workers experienced muscle strain, stress, and pain mostly in their lower back. 8 This was in accordance with other study that showed relationship between forceful exertion and lower back pain. ${ }^{9}$ This study was also consistent with the finding of the other previous studies of neck along with the shoulder pain. The symptoms of neck and shoulder pain were also significantly related to the repetitive work relating to concentration and moving head frequently. ${ }^{10}$ Minor eye injuries were very common during sugarcane harvesting. Dust particles could easily enter inside the eye. A study showed the number of injuries $(36.7 \%)$ caused due to sugarcane leaves. ${ }^{11}$ Similarly, this study also showed $41.7 \%$ injury by mixed cause and mostly by sugarcane leaves resulting in eye watering, eye pain and itching. This study is not consistent with another study which has shown that $16 \%$ had suffered from the skin problems ${ }^{12}$ whereas prevalence has increased in this study. Fifty one percent harvesters had problems related to the skin. The cause of it may be because of the knowledge and practice of hygiene problems among the harvesters. Another set of health problems for sugar cane harvesters are respiratory diseases due to constant exposure to the dust particles comprising nearly to $37 \% .{ }^{13}$ This health problem was consistent with this study as approximately $35.4 \%$ harvesters had either kind of respiratory problems in the form of dry or 
productive cough. All these data show a consistent message.

Notably, this study has found contradict results as compared to one of the study where wrists pain was less prevalent than in our study. Result of our study showed $84.4 \%$ prevalence of hand and wrist joint pain whereas the result of the other study found $14 \%$ prevalence of hand/wrist pain. ${ }^{14}$ It was probably because of the use of local heavy instruments to cut the sugarcane. If the instrument used for sugarcane cutting such as sickle were sharp, the applied force needed to chop the sugarcane stem would have been easier minimizing the strain on wrist joint. Most of the harvesters

\section{REFERENCES}

1. Rossi-Rocha F, Palucci Marziale M, do Carmo Cruz Robazzi M. Poverty as a predisposing factor of illness tendencies in sugarcane workers. Rev Latino-Am 2007; 15: 736-41.

2. Juttel LP, Esforço físico excessivo busca aumento de renda. Cienc Cult. 2008;60(4):6-7.

3. Clementson CL, Hansen AC. Pilot study of manual sugarcane harvesting using biomechanical analysis. J Agric Saf Health 2008; 14: 309-20.

4. Crawford JO. The Nordic Musculoskeletal Questionnaire. Occupational medicine. 2007; 57: 300-301

5. Martha J, Sanders M. Ergonomics and the Management of Musculoskeletal Disorders. 2nd ed. Saint Louis, MO: ButterworthHeinemann. 2013.

6. Shan CL, Bin Adon MY, Rahman AB, Hassan ST, Ismail KB. Prevalence of neck pain and associated factors with personal characteristics, physical workloads and psychosocial among male rubber workers inFELDA settlement Malaysia. Glob J Heal Sci. 2011;4:94-104.

7. National Institute for Occupational Safety and Health. Simple solutions: ergonomics for farm workers (Report No. 2001-111). Accessed March5, 2014.

8. Hoogendoorn WE, Bongers PM, de Vet HC, et al. Flexion and rotation of the trunk and lifting at work are risk factors for low back pain. were local, not trained and used available instruments.

\section{CONCLUSION}

The result of our study showed that the overall occupational health consequences are amongst the common consequences in most of the occupation. Foreign body in the eye, allergic conditions and musculoskeletal pain were the most prevalent occupational health consequences during the work.

\section{Limitation of the study}

Study duration for data collection was the limitation factor in this study as harvesters were not regularly and consistently harvesting in study period.

\section{Spine. 2000; 25:3087-3092.}

9. Rosecrance J, Rodgers G, Merlino L. Low back pain and musculoskeletal symptoms among Kansas farmers levels in a highly repetitive task .Am J Ind Med. 2006; 49:547556.

10. Silverstein, B., Fine, L. J., \& Armstrong, T. J. Hand wrist cumulative trauma disorders in industry. British journal of industrial medicine. 1996;43(11), 779-84.

11. Andersen, J. H., \& et al. Risk factors in the onset of neck/shoulder pain in a prospective study of workers in industrial and service companies; Occupational and Environmental Medicine, 2003;60, 649-654.

12. Goel R,Malik K.P, Goel A, Sharma N, Aggarwal A. Nepal J Ophthalmol.2013 JanJun;5(1):45-9.

13. Rahul Bisht et al. A Descriptive Study on Prevalence of Occupational Health Hazards among Employees of Selected Sugarcane Factory in Deharadun, Uttarakhand, IOSR Journal of Nursing and Health Science, Volume 5, Issue 4 Ver. II Jul. - Aug. 2016.

14. Vasave. S.Y, Anap D. B. Prevalance of musculoskeletal disorders among sugarcane workers - A cross sectional study. Indian Journal of Basic and Applied Medical Research; March 2016: Vol.-5, Issue- 2, P. 756 -762 .

Citation: Thapa B, Sharma A. Prevalence of Occupational Health Consequences During Sugarcane Harvesting Among Harvesters of Morang District JCMS Nepal. 2019; 15(2):128-31. 